\title{
A smart textile system to detect urine leakage
}

\author{
Martínez-Estrada. Marc, Gil. Ignacio, and Fernández-García. Raúl
}

\begin{abstract}
In this paper a wearable system with a sensor embroidered on a textile substrate to detect urine leaks is presented. The system consists of a moisture textile capacitive sensor together with the signal conditioning and its wireless transmission to the cloud. The proposed system has been integrated on underwear and hospital sheet to detect the urine leakage on the diaper users and critical ill patient, respectively. The methodology used by the microcontroller to measure the sensor value is a charge/discharge method. The information is visualised through a computer or smartphone, where can be seen the current state of the sensor. The system has a warning set up to communicate any urine leakage. The experimental results show the functionality of the proposed system which could supply a new tool to hospitals, nursing homes or other institutions to detect when the patient diaper or sheet need to be removed. This tool can optimise the hospital protocol and improve the patient quality of life.
\end{abstract}

Index Terms - leakage, moisture, sensor, smart-textile, textile, urine, wearable.

\section{INTRODUCTION}

$\mathbf{N}$ OWADAYS the world of smart textiles and wearables is growing due to the interest of people to be concerned about the world around them and how are they interacting with it. One of the most interesting fields are on-body sensors, which can provide information in the field of healthcare [1], [2], physical training [3], [4], emergency rescue service and law-enforcement[5]. Several wearable devices demonstrate their functionality and viability on the market to analyse several biological fluids [6] or evaluation of a patient with Parkinson's disease[7].

In order to introduce wearable sensor in our daily life, the clothes or textile substrates are considered one of the best options. Day by day, people cover all their body with clothes or textiles, which makes the fabric the best option to integrate the sensor and prevents from having additional devices with us. As textile industry is growing to cover the demand of the world, this is provoking that the manufacturers search how to increase the value of the products to differentiate from their competitors. Sensor integration over textile increases the value of the fabrics providing a wide range of possibilities for each

An earlier version of this paper was presented at the FLEPS 2020 Conference and was published in its Proceedings "A wearable system to detect urine leakage based on a textile sensor" DOI:10.1109/FLEPS49123.2020.9239554 https://ieeexplore.ieee.org/document/9239554. Paper submitted to IEEE Sensor Journal on December 1st, 2020 This work was supported by Spanish Government-MINECO under Project TEC2016-79465-R and AGAUR-UPC(2020 FI-B 00028).

Martinez-Estrada, Marc is with the Universitat Politècnica de Catalunya, ESEIAAT, 08222 SPAIN (e-mail: marc.martinez.estrada@upc.edu).

Gil, Ignacio is with the Universitat Politècnica de Catalunya, ESEIAAT, 08222 SPAIN (e-mail: ignasi.gil@upc.edu).

Fernández-García, Raúl is with the Universitat Politècnica de Catalunya, ESEIAAT, 08222 SPAIN (e-mail: raul.fernandezgarcia@upc.edu).. textile and it could be one of the methods that increases the value of the products.

To introduce the sensor in a textile substrate there are different techniques. In references [8], [9] ink-jet printing technique were used to develop a moisture sensor with a measurement range of $20-95 \%$ of relative humidity. In reference [9] a moisture sensor with a sensitivity between 0.0559 and $-0.470 \log (\mathrm{Z}) / \% \mathrm{RH}$ with a linearity of 0.8253 to 0.9351 , respectively, was presented. Coating is another technique to integrate sensor over textile. On [10], [11] a breathing sensor based on humidity shift was developed over a textile substrate by applying a conductive coating. In reference [12], [13] a dip coating process is used to develop a sensor capable to measure humidity. Relative humidity was measured on the range from 60 to $90 \%$ of humidity sensor. Last but not least, the conductive yarns can be introduced in the manufacturing process (woven or knitted) or embroidery, In references [14]-[18] these techniques were used to develop different types of moisture sensor from digital ones, which distinguish between dry or wet, to analog ones, which measure between a range of $20 \%$ to $95 \%$

Every technique has pros and cons, for example ink jet printing technique could have the best performance, in the same conditions as other techniques, due to the precision of the process but it still has to improve its washing resistance. Reversely, embroidery technique is the most cost-effective technique, providing good behaviour of the sensor, low cost, good washing resistance and fast prototype construction.

Urine leakage, enuresis and others diseases related with moisture are problems with a high social and economic cost. Urine leakage can affect up to $33 \%$ of patients in health centres [19]. Moreover, associated with moisture problems there are a lot of consequences as an infections or injuries. Despite of some of these problems can be solved by means of diapers, 


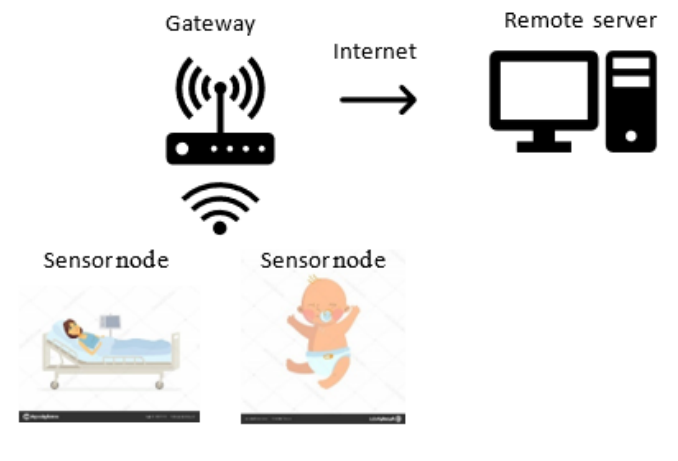

Fig. 1: System architecture.

long time between the substitution of the diaper can produce injuries and infections, due to long time exposure to soaked diaper. As a consequence, nurses, who works at hospitals or retirement homes, must check periodically the diapers or the sheets to reduce the periods where the patient is in contact with the moisture.

Achieving a complete textile integration of the system provides a low impact in user comfort and improves its usability. This fact may help users and medical staff to use the system without fear or concerns. Moreover, the integration of the sensor on underwear or sheet can provide real-time information of the humidity. This information allows to react and take actions without affecting the well-being of the patient.

To gather information of the textile sensor a unit control (UC) with communication interface is required such as [12], [20]-[22].

To guarantee the wearability the UC should be smaller than a buckle belt, in order to be attached in any place of the bed structure or on the waistline.

In this paper, a new wearable system to detect urine leakage based on a textile sensor is presented. This system can help to nurses or healthcare staff in their daily work and to optimise their time and improve the quality of life of their patients.

\section{Materials And Methods}

\section{A. System Architecture}

Figure 1 shows the architecture of the system. It is based on a textile sensor node, gateway and remote server. The textile sensor node is in charge of obtaining the patient information and wireless transmitting to the gateway, which is being configured to receive the data and write it in a database by means of internet connection. The remote server obtains the values of the sensor and shows them on a user interface. The developed system provides a real-time data collection and should give the mechanism to the hospital and nursing home staff to control multiple points and at the same time take actions when it is needed.

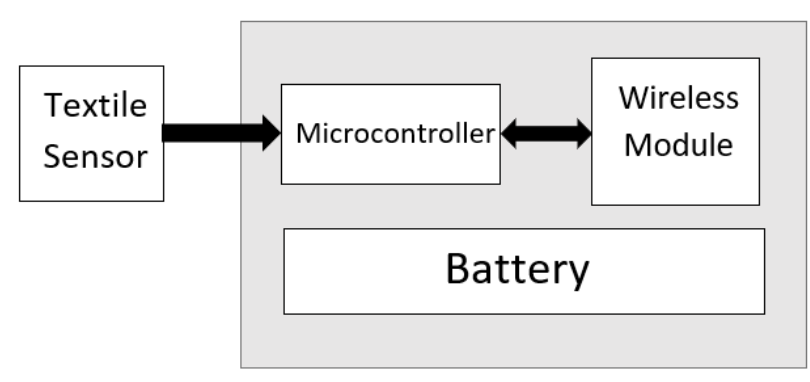

Fig. 2: Unit Control diagram

\section{B. Sensor node}

Figure 2 illustrates the block diagram of the proposed textile sensor node.The core of the wearable system is the textile sensor. This sensor is based on a interdigitated structure embroidered over a textile substrate. Once moisture change produces a shift in the substrate properties, which impact on the sensor behaviour. The textile sensor is connected to the UC through conductive yarns. The UC measures the capacitance from the interdigitated structure and transmits it by means of wireless communication. The textile sensor node is supplied by a battery. The aim is to achieve a system able to obtain the data and send it with the minimum size. The different parts of the system are described as follows:

1) Textile moisture sensor: To sense the moisture, a capacitive sensor was used due to the higher sensitivity in front of resistive sensor. This is due to resistance is affected by other parameters that could interfere on the measurement, such us temperature. Capacitance value of the sensor is given by the dimensions of the pattern (geometrical properties) and materials properties(permittivity). In our case the geometrical properties remains constant meanwhile the moisture produce a shift on the permittivity of the textile material and therefore a change on the capacitance. The equation 1 describes the capacitance value on a interdigitated structure and it was obtained from[23].

$$
\begin{gathered}
C_{R H}=\left(\varepsilon_{R H}+1\right) l\left[(N-3) A_{1}+A_{2}\right](p F) \\
A_{1}=4.409 \tanh \left[0.55 \frac{h^{-0.45}}{W}\right] 10^{-6}\left(\frac{p F}{\mu m}\right) \\
A_{2}=9.92 \tanh \left[0.52 \frac{h^{-0.5}}{W}\right] 10^{-6}\left(\frac{p F}{\mu m}\right)
\end{gathered}
$$

Where:

$C_{x}=$ capacitance from textile sensor

$\varepsilon=$ Permittivity of dielectric

$1=$ Length of fingers

$\mathrm{N}=$ Number of fingers

$\mathrm{h}=$ height of the substrate material

$\mathrm{W}=$ width of the conductor material 


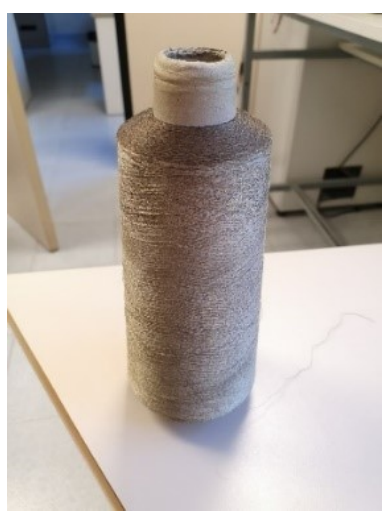

(a) Shieldex Yarn

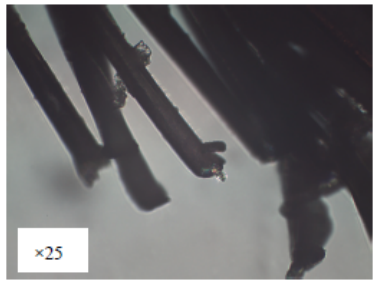

(c) Shieldex yarn on a microscope

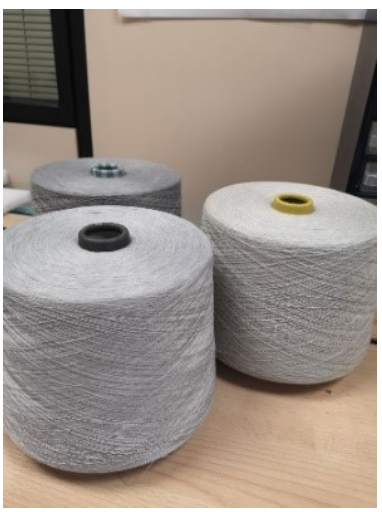

(b) Bekaert yarn

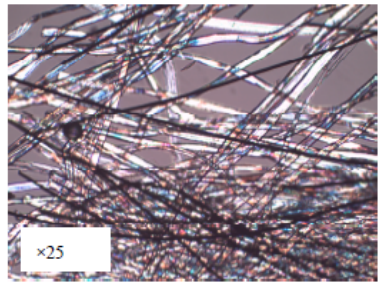

(d) Beakert yarn on a microscope
Fig. 3: Conductive yarns

The sensor developed is an embroidered sensor over a textile substrate, which can be a cotton sheet or a polyester/cotton mix underwear. This sensor could be embroidered with different conductive yarns, different substrate material and with different stitch density. Regarded to conductive yarns two types has been evaluated. The first yarn is a commercial Shieldex 117/17 made by 17 filaments of polyamide coated (Figure 3a). The second kind of yarns are a commercial Bekaert made by cotton or polyester fibres mixed with stainless steel (Figure $3 b$ ), which are similar in touch with conventional yarns due to they are produced by ring yarn method. Properties of the yarns are summarised on Table I. Previous results obtained by the authors [24] shows that Shieldex yarns are more stable and has lower linear resistance than Bekaert yarns. Therefore, the Shieldex yarn was chosen to embroidery the capacitive textile sensor by means of Singer Futura XL-550 embroidery machine using a satin fill stitch structure due to the best homogeneous yarn distribution. In Figure 4 it can be observed the pattern and how it is distributed along the substrate.

Different substrates materials are found in the market. Between them, polyester and cotton are the most commonly fabric substrates used on textile home and clothes. The substrate is the key parameter for sensor behaviour, depending of the substrate material different sensitivities are obtained, which are explained by the different properties of the materials and chemical treatments. Previous works from the authors[24], [25] shows how variation on yarn or substrate material directly.The conclusions from these works are used to choose the materials to build the sensor. The proposed system has been integrated on two different applications, underwear and medical sheets. In case of underwear application (Figure 5) a
TABLE I: Properties for the yarns tested on previous works [24]

\begin{tabular}{|c||c|c|c|}
\hline Properties & Shieldex & $\begin{array}{c}\text { Bekaert } \\
\text { (PES) }\end{array}$ & $\begin{array}{c}\text { Bekaert } \\
(\mathrm{CO})\end{array}$ \\
\hline \hline $\begin{array}{c}\text { Density } \\
\text { (tex) }\end{array}$ & $11.7 / 2$ & $20 / 2$ & $20 / 2$ \\
\hline $\begin{array}{c}\text { Linear R } \\
(\Omega / \mathrm{cm})\end{array}$ & 30 & 50 & $35-70$ \\
\hline $\begin{array}{c}\text { Thread } \\
\text { type }\end{array}$ & $\begin{array}{c}\text { Twisted } \\
\text { multifil. }\end{array}$ & $\begin{array}{c}\text { Ring } \\
\text { yarn }\end{array}$ & $\begin{array}{c}\text { Ring } \\
\text { yarn }\end{array}$ \\
\hline
\end{tabular}

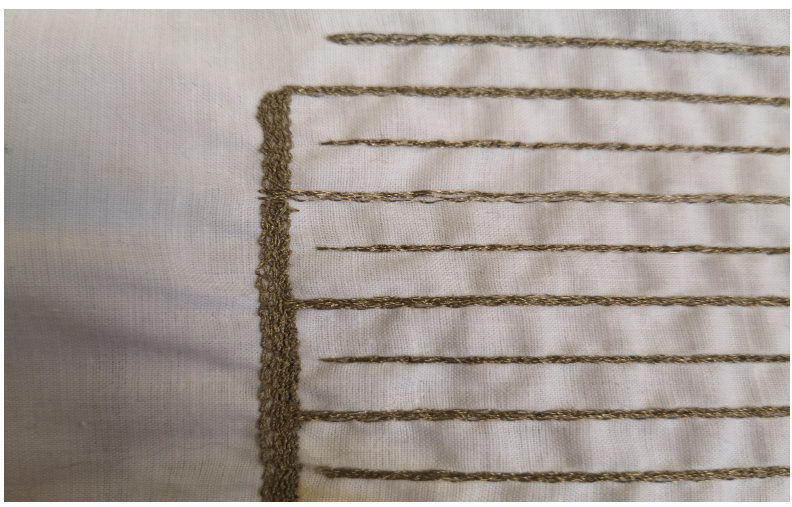

Fig. 4: Detail of the embroidered pattern

mixed cotton polyester fabric was chosen as a substrate which is the most common textile used for underwear production, meanwhile for application on sheets (Figure 6) a cotton fabric was used, which is the material used to produce the medical sheets.

Related with the parameters of the interdigitated sensor, area of measurement was the first requirement to consider. Both applications need different areas of sensing due to the fabric available width. For example, on the sheet, the zone of interest was selected by the urinary leakage's zone and risk zones where sores are more common. Then the space

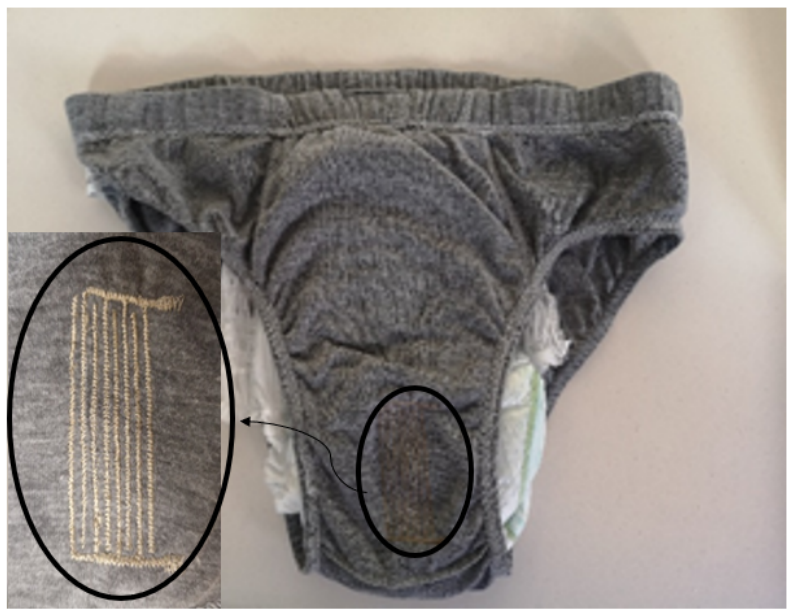

Fig. 5: Underwear embroidered 


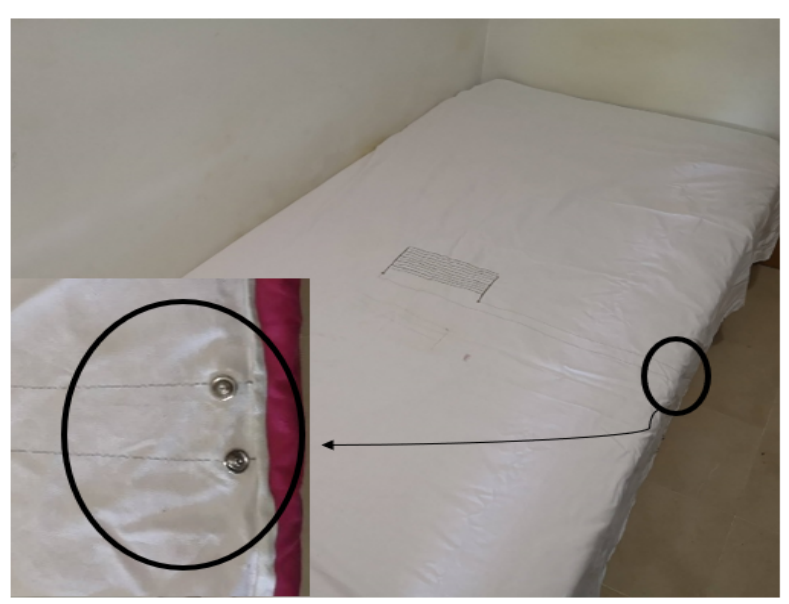

Fig. 6: Sensor embroidered on a sheet

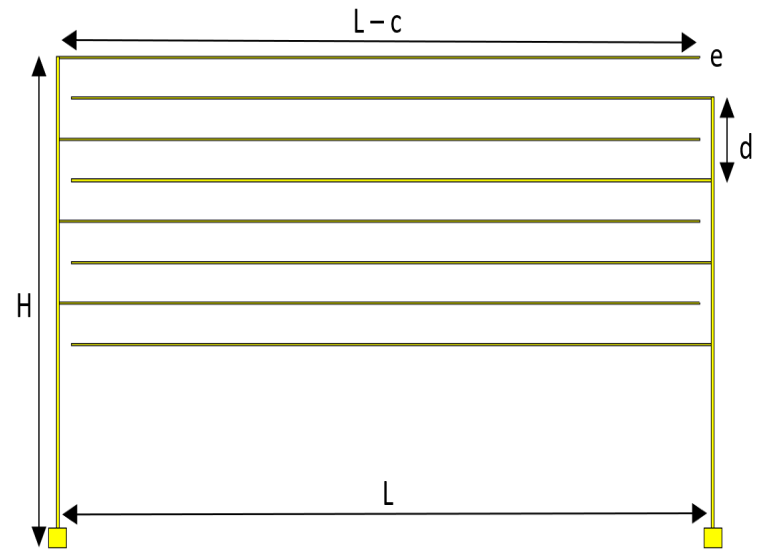

Fig. 7: Sensor design on CST Studio

between lines and the number of lines where determined by means of CST simulation software, in order to obtain a readable value by means of ADC. On the Figure 7 the design parameters are defined: height $(\mathrm{H})$, length( $\mathrm{L})$, distance between lines(d), distance between vertical and horizontal lines(c), line thickness(e) and pair of fingers (n)

In [24] the equivalent circuit of the sensor was previously demonstrated by the author. Which corresponds with a RC parallel lumped model. Figure 8 shows how the equivalent circuit of the textile sensor perform along a variation of the relative humidity swept. It is shown that the behaviour of the sensor changes along the humidity swept. Parallel resistance decreases abruptly, due to an increase on the conductivity of the material, from $5.7 \mathrm{M} \Omega$ to $11.3 \mathrm{k} \Omega$, between 50 to $90 \%$. Related with the parallel capacitance the behaviour is

TABLE II: Dimensions of sensors presented

\begin{tabular}{|c||c|c|c|c|c|c|}
\hline Parameters & $\begin{array}{c}\mathrm{H} \\
(\mathrm{mm})\end{array}$ & $\begin{array}{c}\mathrm{L} \\
(\mathrm{mm})\end{array}$ & $\begin{array}{c}\mathrm{d} \\
(\mathrm{mm})\end{array}$ & $\begin{array}{c}\mathrm{c} \\
(\mathrm{mm})\end{array}$ & $\begin{array}{c}\mathrm{e} \\
(\mathrm{mm})\end{array}$ & $\mathrm{n}$ \\
\hline \hline Underwear & 30 & 69 & 2 & 2 & 1 & 4 \\
\hline Sheet & 150 & 220 & 8 & 4 & 2 & 4 \\
\hline
\end{tabular}

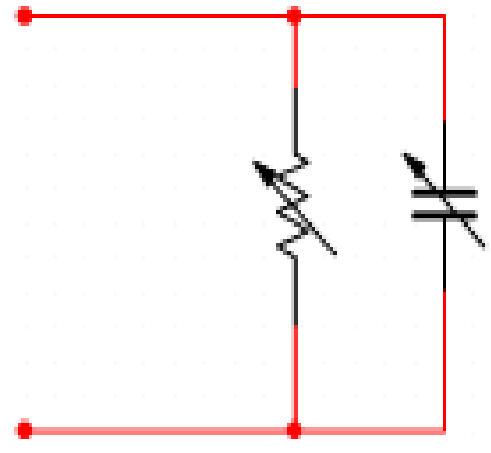

(a) Scheme

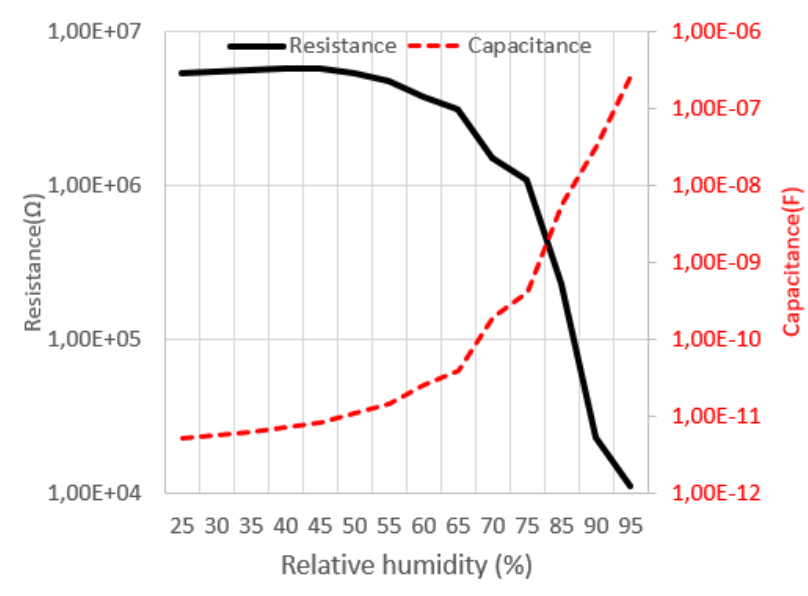

(b) RC measured values

Fig. 8: Equivalent circuit obtained of the sensor

the opposite. The capacitance range increase from $7.3 \mathrm{pF}$ to $26.9 \mathrm{nF}$.

2) Unit Control: The UC is based on the microcontroller SAM D21 family [26] provided by Microchip and a wireless interface NINA-W10 from u-blox which provide WiFi and Bluetooth connectivity[27]. The main microcontroller characteristics are low-power, 32-bit Cortex-M0+ MCU with Advanced Analog to Digital Converter (ADC) and Pulse Witdh Modulator (PWM).

UC location depends on the application. When textile sensor connected to the UC is integrated on a sheet, the device will be attached to the bottom face of the bed where the sheet and the UC are going to be connected. In this case UC will be connected to an external power source, e.g. in hospitals should have near to the bed other electronic devices to monitor the patient and UC can be connected as well without any inconvenient to the patient comfort and safety. On the other side, Underwear application imply a battery attached to the UC. But as the UC has a low power microcontroller, the battery is planned to be as small as possible. The microcontroller used on the board consume $40 \mathrm{~mA}$ meanwhile is connected to the $\mathrm{WiFi}$, on the measurements it might consume till $80 \mathrm{~mA}$. The measurements duration is less than 1 second. Considering these facts, the battery necessary to feed the UC will spend 80 
$\mathrm{mAh}$, if it is measuring every second. It could be decreased to hardly $40 \mathrm{mAh}$ if the measurements are done in a large space of time. If the measurement is taken every 2 seconds and take into account 5 seconds preparing the communication, the sensor will consume 60mAh. It means that with a $1200 \mathrm{mAh}$ battery, which size is similar to a buckle belt, the sensor will have a 20 hours of battery life. Despite the fact that consumption is high, it is necessary to take into account that low power strategies has not been applied on this application.

The textile sensor is connected to the UC by a snap, two lines made by conductive yarn go till the border of the sheet or the underwear where two snaps connect with the microcontroller as it is shown on Figure 6(inset).

The capacitance of the textile sensor is measured by the microcontroller's ADC based on charge/discharge method[28]. Figure 9 shows the connection diagram used to measure the capacitance value. First, the terminals are connected to $0 \mathrm{~V}$ to guarantee that the capacitance is discharged. Hereafter, A0 terminal is set at $5 \mathrm{~V}$, this voltage charges $\mathrm{Cx}$ (textile sensor) and the $20 \mathrm{pF}$ internal capacitance (Figura 9a). When $\mathrm{Cx}$ is charged, the voltage at A2 terminal is measured and the $\mathrm{Cx}$ value is obtained by means of equation (4).

$$
C_{x}=\frac{V_{\text {out }}}{V_{\text {in }}-V_{\text {out }}} C_{\text {int }}
$$

Where:

$$
\begin{aligned}
& C_{x}=\text { capacitance from textile sensor } \\
& \mathrm{V}_{\text {out }}=\text { Voltage on } A 2 \\
& \mathrm{~V}_{\text {in }}=\text { Voltage on } A 0 \\
& \mathrm{C}_{\text {int }}=\text { internal capacitance in pin } A 2(20 \mathrm{pF})
\end{aligned}
$$

When the A2 terminal voltage reaches values reach $4.8 \mathrm{~V}$, which means that $\mathrm{Cx} \gg 20 \mathrm{pF}$, a different characterisation method is used. The connection circuit is shown on Figure $9 \mathrm{~b}$. The A2 pin is configured as an input terminal with a pullup resistance and A0 pin is set a $0 \mathrm{~V}$. At that moment the $\mathrm{Cx}$ starts to charge and the charge time is measured with an internal counter. The $\mathrm{Cx}$ value in this situation is calculated using the equation (5).

$$
C_{x}=\frac{-t / R}{\ln \left(1-\frac{V_{\text {out }}}{5}\right)}
$$

Where:

$C_{x}=$ capacitance from textile sensor

$\mathrm{V}_{\text {out }}=$ Voltage on $A 2$

$\mathrm{R}=$ Pull-up resistance $(40 \mathrm{k} \Omega)$

$\mathrm{t}=$ charge time

Once the capacitance value is obtained, it is saved on the UC and wireless transmitted to the gateway by means of HTTP protocol. Figure 10 summarise this measurement and communication procedure. The whole procedure needs about 1.5 seconds to be completed in order to guarantee the charge and discharge of the capacitance.

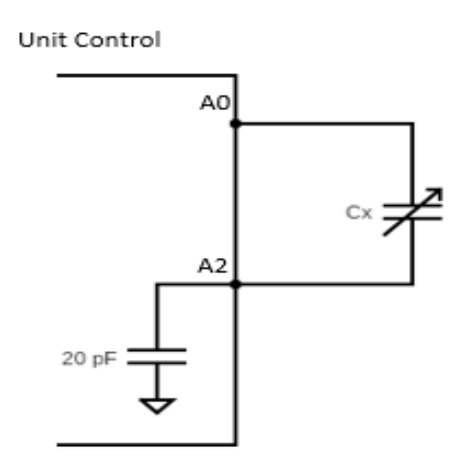

(a) Circuit on $\mathrm{pF}$ measurement range

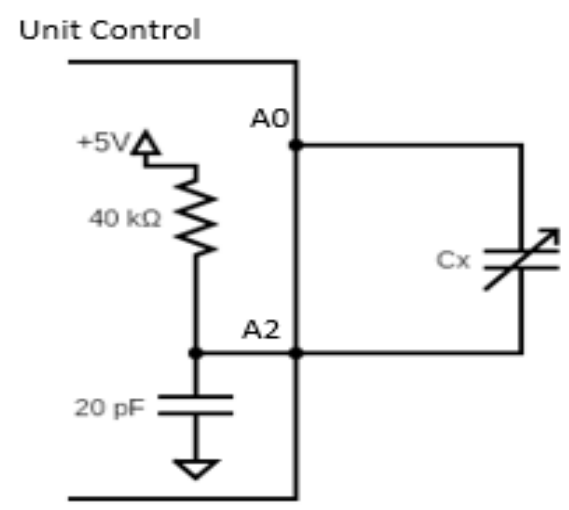

(b) Circuit on $\mathrm{nF}$ or $\mathrm{uF}$ measurement range

Fig. 9: Measurement circuits of the textile sensor value

\section{Remote server}

The remote server is in charge of the storage of the information provided by the sensor node on a specific database and real-time visualisation on a graphic user interface. To develop the database and HTTP Apache web server, the XAMPP program was chosen. This package is intuitive, easy to implement and with a large community behind that give support and provide enough information to easily build up any application based on MySQL database. The XAMPP control panel is shown in Figure 11

The database developed is shown on Figure 12. The database structure consists of three fields; id, raw data and time stamp. The id identifies the sensor node. The raw data stores the capacitance value measured and the time stamp point out once the measurement was done. To guarantee the write permissions on the database the id of the sensor nodes is previously defined on the database. If it is required fields on the database can be added, for example, battery life time. The database information will be used to take actions, such as to detect the urine leakage time stamp.

Figure 13 shows the developed graphic user interface (GUI) developed with Grafana. The Grafana open source software was selected due to its compatibility with MySQL database. The abscissa axis represents the measurement time stamp and 


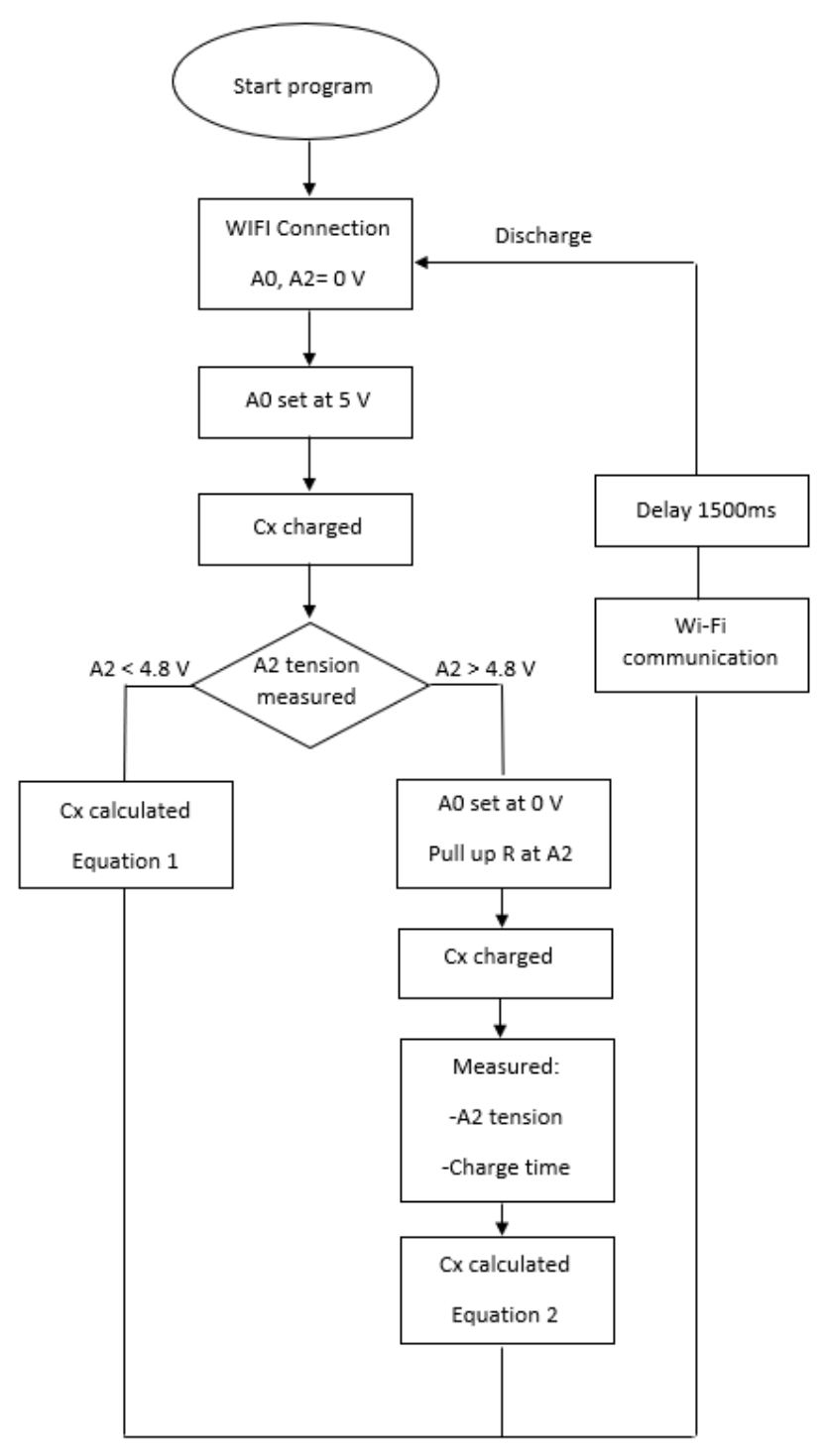

Fig. 10: Routines to calculate capacitance

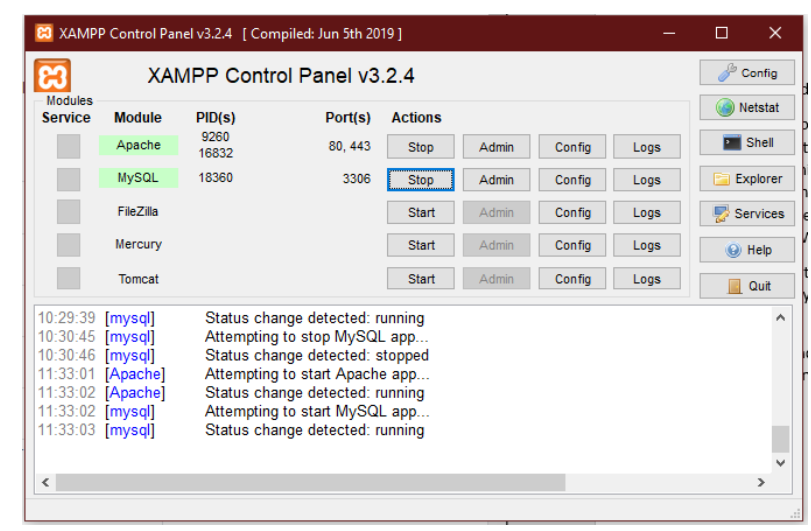

Fig. 11: XAMPP control panel

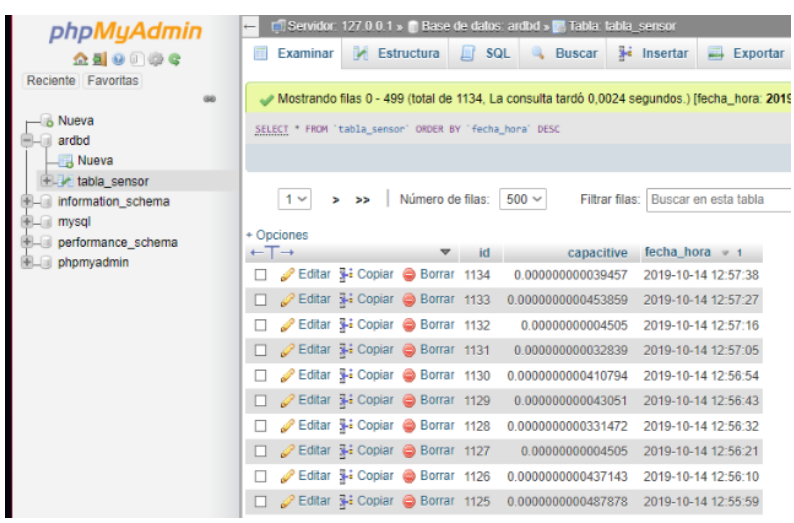

Fig. 12: Database table filled by the board

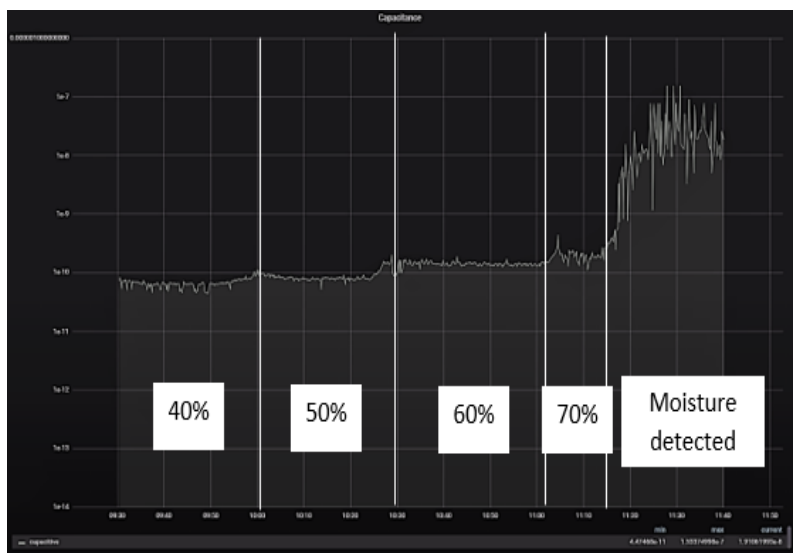

Fig. 13: Example of Grafana graph

ordinate axis the measured textile sensor capacitance. It is observed the sensor response when the moisture is swept from $40 \%$ RH up to moisture saturation. From $40 \%$ to $70 \%$ slightly changes are observed on the sensor capacitance. However once moisture saturation is achieved the sensor capacitance suddenly increases. This fact is used in order to detect when the urine leakage takes place. The staff from hospitals and nursing homes can check the humidity state of each sensor node through the GUI.

\section{Results And Discussion}

The aim is to demonstrate that the system proposed works and it is able to obtain the variations in relative humidity and therefore to detect once the urine leakage is produced.

In previous works the sensor demonstrated its functionality. This paper expands the previous results adding the sensor signal conditioning, processing and transmission. That includes the capability of the charge/discharge characterisation method to read the textile sensor capacitance, the UC and the remote server functionalities.

Two different results are shown. On the one hand, the proposed charge/discharge method and the Rohde \& Schwarz HM8118 LCR meter measurements are compared. On the other hand, a leakage detection test was performed to shown how the system works. Both results are obtained on two different fabrics, the underwear and the medical sheet. 


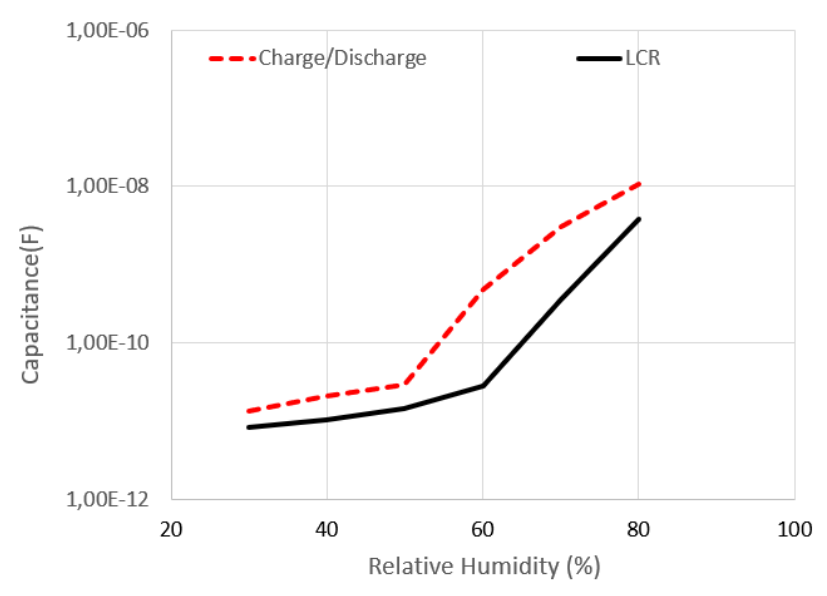

Fig. 14: Sensor on underwear measured with LCR meter and Charge/discharge method from $30 \% \mathrm{RH}$ to $80 \% \mathrm{RH}$

The test to compare the sensor values measured by the LCR and Unit Control was performed on a CCK-25/48 Dycometal climatic chamber. The sensor is prepared inside with a holder. the sensor is placed in the middle of the chamber connected with the LCR $(0,1 \%$ measurement error[29]) or the microcontroller depending on the test performed. A computer connected to the climatic chamber controls the swept of the relative humidity. Values were obtained over an average of the values obtained for the different sensors embroidered.

\section{A. Underwear}

The embroidered sensor on an underwear was characterised. On Figure 14 a swept from $30 \%$ to $80 \%$ of relative humidity $(\mathrm{RH})$ is shown. Capacitance is directly affected by a $\mathrm{RH}$ change due to the change in permittivity of the substrate when absorbing humidity. In the graph it is plotted the measurement results obtained for both, the external LCR meter and the charge/discharge proposed method. It is observed that the capacitance value for $30 \% \mathrm{RH}$ is about $10 \mathrm{pF}$ and it reaches about $10 \mathrm{nF}$ for $80 \% \mathrm{RH}$. Despite of the values obtained for both measurement methods are slightly different, it does not have any impact on the system functionality because the system only needs to determinate if the system reaches a certain threshold value $(10 \mathrm{nF})$.

A test with the diaper was performed to observe the sensor functionality in a real situation, where the measurements were visualised from Grafana. The sensor was located under the diaper (Figure 5) with the sensing area oriented along the diaper.

The volume of a miction for a baby or child is between 80-100 ml.To simulate urine, $100 \mathrm{ml}$ of water were used to observe how the sensor reacts with a miction.

The diaper characteristics absorb around $240 \mathrm{ml}$ of water without giving to the user wet feeling. After 600 seconds, 100 $\mathrm{mL}$ of water were poured into the diaper to simulate a urine leakage. As observed in Figure 15 once the urine leakage is produced, the sensor capacitance increases instantly due to the diaper abortion, which expels moisture from the inside of the diaper to the outside, providing a drying feeling for the user.

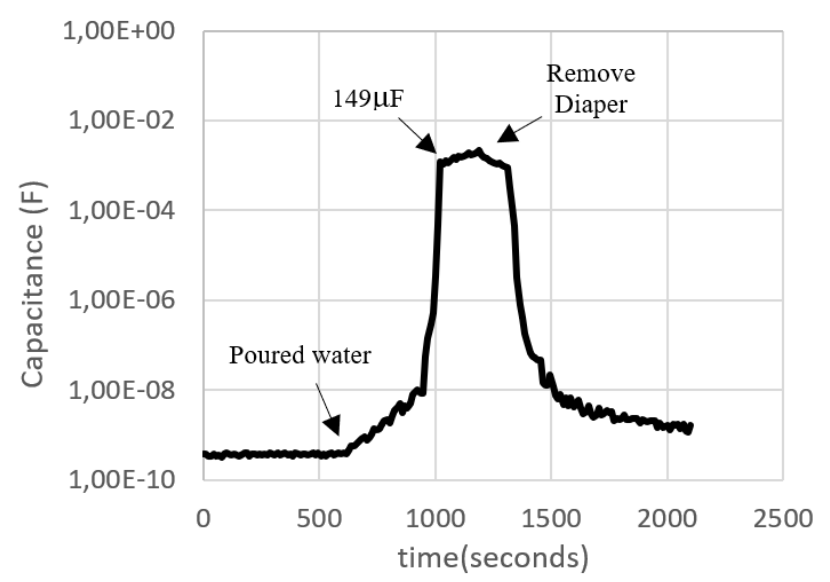

Fig. 15: Sensor capacitance evolution when $100 \mathrm{~mL}$ of water are poured on the diaper

The outer part of the diaper starts to being wet because that flux of moisture. It is observed that in less than 120 seconds the capacitance value from the sensor changes significantly, from $37 \mathrm{pF}$ to $149 \mu \mathrm{F}$, which is the highest point in the graph. Notice that before pouring the water, the capacitance is $37 \mathrm{pF}$ which corresponds with an environmental humidity of about 55\% according to sensor behaviour measured with the charge/discharge method. When the diaper was removed to study the recovery time the sensor capacitance was reduced up to $126 \mathrm{pF}$ in 600 seconds. The sensor capacitance does not recover the original capacitance, which can be treated as hysteresis, due to hydrophilic behaviour of the cotton that still has moisture inside. However, this point it is accepted as recovered, since it is possible to start another detection without expect false detection.

\section{B. Cotton sheets}

In this case the textile sensor has increased its size, to increase the detection area. This is due to the requirements need for this application (Figure 6).

In Figure 16 the sensor value measured by means LCR and charge/discharge method is shown. A swept from $40 \%$ to $90 \%$ of relative humidity $(\mathrm{RH})$ is performed. It is observed that the capacitance value for $40 \% \mathrm{RH}$ is about $250-300$ $\mathrm{pF}$ and it reaches up to $20 \mu \mathrm{F}$ for $90 \% \mathrm{RH}$. Although the characterisation behaviour observed in both methods are different, the values measured on wet and dry condition are similar. Therefore, the proposed system can be used to detect the wet conditions observed when a urine leakage appears.

In Figure 17 the measurement results when a urine leakage is simulated are observed. In this case a adult diaper was used. The quantity of moisture that an adult diaper can absorb is almost 10 times more than a baby diaper. The miction volume for an adult is between $250-750 \mathrm{~mL}$. To reproduce this miction $750 \mathrm{~mL}$ of water were poured in the diaper, with the objective to be close to the absorb limit of the diaper. As it is shown on Figure 17 after the $750 \mathrm{~mL}$ were poured, a slight change in the capacitance from $280 \mathrm{pF}$ to $500 \mathrm{pF}$ is detected. After 600 


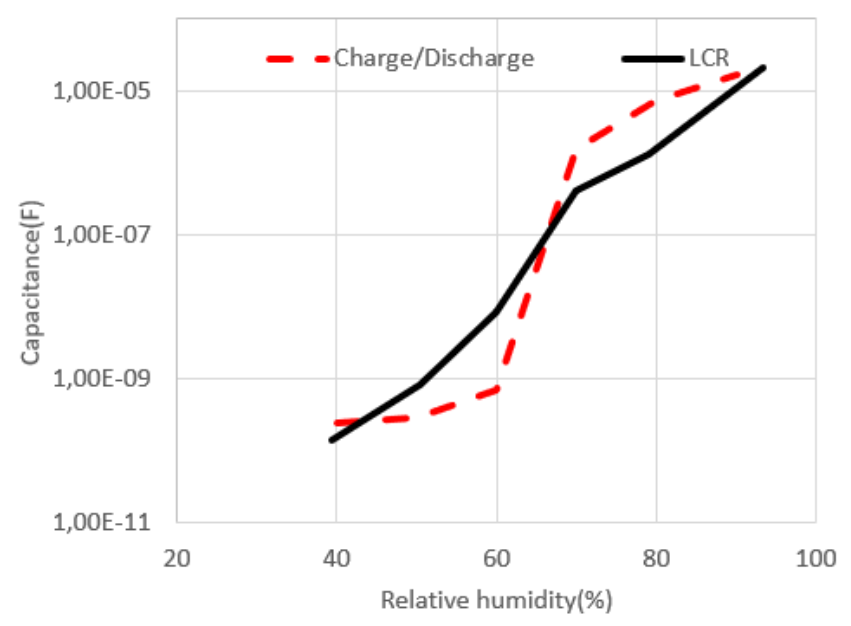

Fig. 16: Sensor on a sheet measured with LCR meter and Charge/discharge method from $40 \% \mathrm{RH}$ to $90 \% \mathrm{RH}$

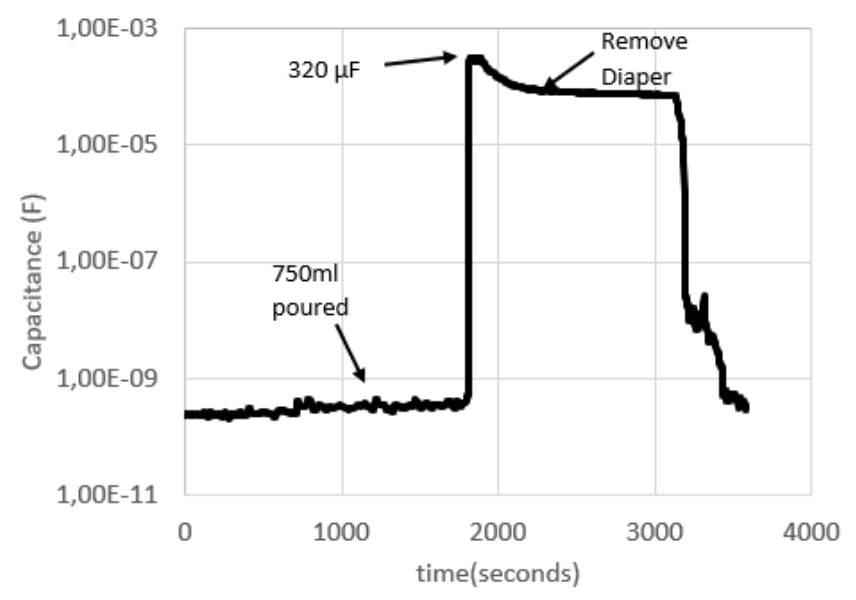

Fig. 17: Sensor on a sheet capacitance evolution when 100 $\mathrm{mL}$ of water are poured on the diaper

seconds the capacitance of the sensor changes abruptly up to $320 \mu \mathrm{F}$. This fact is used to detect the urine miction. Once the diaper is retired and the sheet is dry the capacitance values recover.

The obtained sensitivity of our sensor is between $(-0.034)$ and $(-0.0804) \log (\mathrm{Z}) / \% \mathrm{RH}$ with a linearity between 0.8759 to 0.9875 . Which is slightly higher than previous resource.

\section{CONCLUSION}

A wearable system with a sensor integrated in a textile substrate was presented. The system is composed by a textile sensor, a unit control and a remote server. The system was prepared to obtain the data from the sensor and send it, through WIFI, to a database where it will storage the data, afterwards Grafana will show the data to the medical staff or care personal. The measurement results were compared with conventional equipment on a few test conditions, similar behaviour was observed. The system demonstrates its functionality on both an underwear and a medical sheet to detect
TABLE III: Dimensions of sensors presented

\begin{tabular}{|c|c|c|c|c|}
\hline & $\mathrm{e}(\mathrm{mm})$ & $\mathrm{d}(\mathrm{mm})$ & $\begin{array}{c}\text { Sensitivity } \\
(\log (\mathrm{Z}) / \% \mathrm{RH}\end{array}$ & Linearity \\
\hline \hline Underwear & 1 & 2 & -0.034 & 0.8759 \\
\hline Sheet & 2 & 8 & -0.0804 & 0.9875 \\
\hline $\begin{array}{c}\text { Reference } \\
{[9]}\end{array}$ & 0.2 & 0.25 & $\begin{array}{c}(-0.0496) \\
- \\
(-0.0559)\end{array}$ & $\begin{array}{c}0.8253 \\
- \\
0.9351\end{array}$ \\
\hline
\end{tabular}

urine leakage. Real-time data collected give an opportunity to analyse the information and develop new action protocol on hospitals and home care institutions. Theses protocols can help shorten the time consumed revising the diapers state of the patients. From the patients' point of view, the system improves their quality of life and reduces injuries derived from constant humidity exposure.

Future works will be focused on the integration of the sensor in the weaving process in order to improve the usability of the system proposed. Furthermore, applying low power consumption techniques to improve the battery lifetime is planned.

\section{ACKNOWLEDGMENT}

This work was supported by Spanish Government-MINECO under Project TEC2016-79465-R and AGAUR-UPC(2020 FIB 00028).

\section{REFERENCES}

[1] A. Bhide, S. Muthukumar, and S. Prasad, "CLASP (Continuous lifestyle awareness through sweat platform): A novel sensor for simultaneous detection of alcohol and glucose from passive perspired sweat," Biosensors and Bioelectronics, vol. 117, no. June, pp. 537-545, 2018, ISSN: 18734235. DOI: $10.1016 /$ j. bios . 2018 . 06 . 065. [Online]. Available: https : / / doi.org/10.1016/j.bios. 2018 . 06.065 .

[2] J. Deignan, M. Jacobs, L. Florea, S. Coyle, D. Diamond, M. Pacelli, and R. Paradiso, "Textile piezoresistive sensors for on-body measurement of spinal extension," in Proceedings of IEEE Sensors, 2017, ISBN: 9781479982875. DOI: 10 . 1109 / ICSENS . 2016 . 7808914.

[3] J.-F. Wu, C. Qiu, Y. Wang, R. Zhao, Z.-P. Cai, X.-G. Zhao, S.-S. He, F. Wang, Q. Wang, and J.-Q. Li, "Human Limb Motion Detection with Novel Flexible Capacitive Angle Sensor Based on Conductive Textile," electronics, vol. 7, no. 192, 2018. DOI: $10.3390 /$ electronics 7090192.

[4] H. Baskan, H. Acikgoz, R. Atakan, H. Eryuruk, N. Akalin, H. Kose, Y. Li, S. Kursun Bahadir, and F. Kalaoglu, "Running functional sport vest and short for e-textile applications," IOP Conference Series: Materials Science and Engineering, vol. 254, no. 7, pp. 1-8, 2017, ISSN: 1757899X. DOI: 10 . $1088 / 1757-$ 899X/254/7/072004. 
[5] G. Tartare, X. Zeng, and L. Koehl, "Development of a wearable system for monitoring the firefighter's physiological state," in 2018 IEEE Industrial Cyber-Physical Systems (ICPS), IEEE, May 2018, pp. 561-566, ISBN: 978-1-5386-6531-2. DOI: 10 .1109/ICPHYS . 2018 . 8390767.

[6] G. Matzeu, L. Florea, and D. Diamond, "Advances in wearable chemical sensor design for monitoring biological fluids," Sensors and Actuators, B: Chemical, vol. 211, pp. 403-418, May 2015, ISSN: 09254005. DOI: $10.1016 / j . s n b .2015 .01 .077$.

[7] B. R. Greene, B. Caulfield, D. Lamichhane, W. Bond, J. Svendsen, C. Zurski, and D. Pratt, "Longitudinal assessment of falls in patients with Parkinson's disease using inertial sensors and the Timed Up and Go test," Journal of Rehabilitation and Assistive Technologies Engineering, vol. 5, p. 205566831775081,2018 , ISSN: 2055-6683. DOI: $10.1177 / 2055668317750811$.

[8] J. Weremczuk, G. Tarapata, and R. Jachowicz, "Humidity Sensor Printed on Textile with Use of Ink-Jet Technology," Procedia Engineering, vol. 47, pp. 13661369, Jan. 2012, ISSN: 1877-7058. DOI: $10.1016 / \mathrm{J}$. PROENG. 2012.09 .410$.

[9] P. G. Su and X. H. Lee, "Electrical and humiditysensing properties of flexible metal-organic framework $\mathrm{M} 050(\mathrm{Mg})$ and KOH/M050 and AuNPs/M050 composites films," Sensors and Actuators, B: Chemical, vol. 269, pp. 110-117, 2018, ISSN: 09254005. DOI: 10 . $1016 / j$.snb.2018.05.002. [Online]. Available: https : / / doi .org/10.1016/j.snb. 2018 . 05.002 .

[10] B. Li, G. Xiao, F. Liu, Y. Qiao, C. M. Li, and Z. Lu, “A flexible humidity sensor based on silk fabrics for human respiration monitoring," Journal of Materials Chemistry $C$, vol. 6, no. 16, pp. 4549-4554, 2018, ISSN: 20507526. DOI: $10.1039 / \mathrm{c} 8 \mathrm{tc} 00238 \mathrm{j}$.

[11] R. Razmand, M. N. Dehkharghani, A. Karimpour, and F. Hossein-Babaei, "A Graphene Oxide-Based Humidity Sensor for Wearable Electronic," ICEE 2019 - 27th Iranian Conference on Electrical Engineering, pp. 423426, 2019. DOI: 10 . 1109/IranianCEE . 2019. 8786557.

[12] J. H. Jang and J. I. Han, "Cylindrical relative humidity sensor based on poly-vinyl alcohol (PVA) for wearable computing devices with enhanced sensitivity," Sensors and Actuators, A: Physical, vol. 261, pp. 268-273, 2017, ISSN: 09244247. DOI: $10.1016 / j$. sna . 2017.05 .011$.

[13] Y. Chen, B. Xu, J. Gong, J. Wen, T. Hua, C. W. Kan, and J. Deng, "Design of High-Performance Wearable Energy and Sensor Electronics from Fiber Materials," ACS Applied Materials and Interfaces, vol. 11, no. 2, pp. 2120-2129, 2019, ISSN: 19448252. DOI: 10 . 1021 / acsami. 8b16167.

[14] R. Soukup, A. Hamacek, L. Mracek, and J. Reboun, "Textile based temperature and humidity sensor elements for healthcare applications," Proceedings of the 2014 37th International Spring Seminar on Electronics
Technology, pp. 407-411, 2014, ISSN: 2161-2528. DOI: 10.1109 /isse.2014.6887634.

[15] A. Lund, S. Darabi, S. Hultmark, J. D. Ryan, B. Andersson, A. Ström, and C. Müller, "Roll-to-Roll Dyed Conducting Silk Yarns: A Versatile Material for E-Textile Devices," Advanced Materials Technologies, vol. 3, no. 12, pp. 1-6, 2018, ISSN: 2365709X. DOI: 10.1002 / admt . 201800251.

[16] D. Shuaib, L. Ukkonen, J. Virkki, and S. Merilampi, "The possibilities of embroidered passive UHF RFID textile tags as wearable moisture sensors," 2017 IEEE 5th International Conference on Serious Games and Applications for Health, SeGAH 2017, 2017. DOI: 10 . 1109 /SeGAH.2017.7939286.

[17] P. G. Su and C. F. Chang, "Fabrication and electrical and humidity-sensing properties of a flexible and stretchable textile humidity sensor," Journal of the Taiwan Institute of Chemical Engineers, vol. 87, pp. 36-43, 2018, ISSN: 18761070. DOI: 10.1016/j.jtice. 2018.03 . 050. [Online]. Available: https://doi .org/10. $1016 / j . j t i c e .2018 .03 .050$.

[18] A. Jakubas, E. Lada-Tondyra, and M. Nowak, "Textile sensors used in smart clothing to monitor the vital functions of young children," 2017 Progress in Applied Electrical Engineering, PAEE 2017, pp. 5-8, 2017. DOI: 10.1109/PAEE.2017.8008989.

[19] M. I. Orna-Esteban, J. I. Artero-Muñoz, E. CaldenteyIsern, L. Usieto-López, P. Cuadra, and C. Isanta-Pomar, "Prevalence of urinary incontinence in two urban health centres," Semergen, vol. 37, no. 7, pp. 347-351, 2011, ISSN: 11383593. DOI: $10.1016 / j$.semerg. 2011 . 01.008.

[20] C. C. Vu and J. Kim, "Human motion recognition using SWCNT textile sensor and fuzzy inference system based smart wearable," Sensors and Actuators, A: Physical, vol. 283, pp. 263-272, 2018, ISSN: 09244247. DOI: $10.1016 /$ j.sna. 2018.10.005. [Online]. Available: https://doi.org/10.1016/j.sna . 2018.10.005.

[21] J. Eom, R. Jaisutti, H. Lee, W. Lee, J. S. Heo, J. Y. Lee, S. K. Park, and Y. H. Kim, "Highly Sensitive Textile Strain Sensors and Wireless User-Interface Devices Using All-Polymeric Conducting Fibers," ACS Applied Materials and Interfaces, vol. 9, no. 11, pp. 10190 10197,2017 , ISSN: 19448252. DOI: 10 . $1021 /$ acsami. 7b01771.

[22] T. Roland, K. Wimberger, S. Amsuess, M. F. Russold, and W. Baumgartner, An insulated flexible sensor for stable electromyography detection: Application to prosthesis control, 4. 2019, vol. 19, ISBN: 4373224684. DOI: $10.3390 / \mathrm{s} 19040961$.

[23] M. R. H. V. Beeresha R S, A M Khan, "Design and Optimization of Interdigited Capacitors," IJRET: International Journal of Research in Engineering and Technology, vol. 05, no. 21, pp. 273-277, 1994.

[24] M. Martínez-Estrada, B. Moradi, R. Fernández-Garcia, and I. Gil, "Impact of Conductive Yarns on an Embroidery Textile Moisture Sensor," Sensors, vol. 19, no. 5, 
p. 1004, 2019, ISSN: 1424-8220. DOI: $10.3390 /$ s19051004. [Online]. Available: http : / / www . mdpi.com/1424-8220/19/5/1004.

[25] M. Martínez-Estrada, R. Fernández-Garcia, and I. Gil, "Experimental analysis of fabric substrate on a moisture sensor," The Journal of the Textile Institute, pp. 1-7, 2020.

[26] Microchip Technology Inc., SAM D21 Family Datasheet. 2018, p. 1202. [Online]. Available: https: / / www . microchip . com / wwwproducts / en / ATsamd21g18.

[27] U-blox, NINA - W10 series Datasheet. 2019, p. 48. [Online]. Available: www . u-blox . com.

[28] J. E. Gaitán-Pitre, M. Gasulla, and R. Pallàs-Areny, "Analysis of a direct interface circuit for capacitive sensors," IEEE Transactions on Instrumentation and Measurement, vol. 58, no. 9, pp. 2931-2937, 2009, ISSN: 00189456. DOI: 10 . 1109 / TIM . 2009 . 2016782.

[29] R. Lcr-bridge and S. Hm, "R \& S ® HM8118 Technical Data," vol. 488,

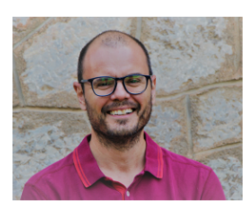

Gil.Ignacio was born in 1978 in Barcelona, Spain. He received degrees in physics and electronics engineering in 2000 and 2003 , and then his $\mathrm{PhD}$ in 2007 from the Universitat Autònoma de Barcelona, Spain. From 2003 to 2008 he was assistant professor in electronics and a researcher with the RF-Microwave Group in the Electronic Engineering Department, Universitat Autonòma de Barcelona, Spain. From 2006 to 2008 he worked for EPSON Europe Electronics $\mathrm{GmbH}$ where he developed high-performance integrated RF CMOS circuits, transceivers and system design. In 2008 he joined the Electronic Engineering Department, Universitat Politècnica de Catalunya (UPC), Spain, as lecturer and researcher. Since 2011 he is associate professor at UPC. Since 2012 he is also a collaborator at Universitat Oberta de Catalunya (UOC), Spain.

$\mathrm{He}$ has been involved in 12 research projects ( 3 as principal researcher) in different research activities including passive and active $\mathrm{RF}$ and microwave devices and circuits, metamaterials, EMC and smart textile electronics. From 2012-2014 he served as Chairman of the Spanish IEEE EMC Chapter. In 2017 he was academic visitor at Loughborough University (UK) in the Wireless Communications Research Group. Since 2019 he is Deputy Director of International Relations at ESEIAAT (UPC).

Dr. Gil is co-author of more than 150 scientific publications and 17 patents. He has been awarded the Duran Farell de Investigación Tecnológica (2006) and the patent award from SEIKO EPSON Corporation (2010). Dr. Gil has been visiting professor in different Universities: New Jersey Institute of Technology (USA), Limerick University (Ireland), Loughborough University (UK), Shaoxing University (China) and Polytechnic University of Tirana (Albania).

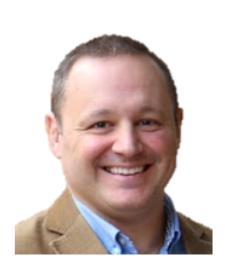

Fernández-García, Raúl. received the B.Eng. degree in telecommunications and M.Eng degree in electronics from the Universitat Politecnica de Catalunya, Barcelona, in 1997 and 1999, respectively. In 2007 he received the Ph.D. degree from the Universitat Autonoma de Barcelona. From 1998 to 2001, he worked for Sony Spain, as Radiofrequency Engineer, where he developed analog and digital TV tuners. From 2001 to 2007, he was part-time Assistant Professor in electronics with the Department of

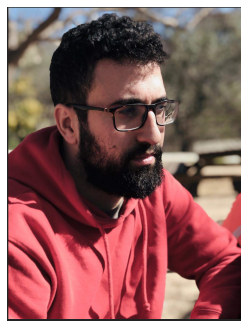

Martínez-Estrada. Marc received the B.Eng degree in Industrial Technologies and M. degree in Industrial Engineering specialised on Textile technologies from the Universitat Politecnica de Catalunya(ESEIAAT), Terrassa(Barcelona) in 2016 and 2018. In 2018 he starts the Ph.D. degree in Electronic Engineering at Universitat Politecnica de Catalunya, which is focused on Smart textiles. From 2015 to 2016 he worked for FirstVision, as a product designer in charge of the design and development of the product, where he starts to introduce himself in the smart textile technology. From 2018 to 2020, he was part-time Assistant Professor in electronics with the Department of Electronics Engineering at Universitat Politecnica de Catalunya. At 2020 he gets a grant for the recruitment of new research staff from AGAUR (FI-2020) and being contracted by the university as a full-time researcher. Mr. Martinez-Estrada is author of 10 papers in international journals and conferences. $\mathrm{He}$ is starting his career as a researcher and focus on his Ph.D. in capacitive sensors integrated on textile substrates that can be helpful for healthcare applications.
Electronics Engineering, Universitat Autonoma de Barcelona. Funded by the European Marie Curie Program, he worked on devices and circuits reliability at IMEC (Belgium) between 2005 and 2006. From 2008 to 2011, he was full-time Assistant Professor in the Department of Electronics Engineering, Universitat Politecnica de Catalunya. At present he is Associate Professor at the same department.

Dr. Fernandez-Garcia is author or a co-author of more than 110 papers in international journals and conferences. He was the recipient of Best Paper Awards at IPFA 2007. His current scientific interest is focused on wearable sensor development for sport and health applications. 